\title{
Modeling and Analysis of container chassis using FEM.
}

\author{
C. Madan Mohan Reddy, Dr M. Lakshmi Kantha Reddy ${ }^{2}$ \\ *Asst.Professor, Dept. of Mechanical Engineering, Mother Theresa Institute of Engineering \& Technology \\ Palamaner. \\ ** Principal, Mother Theresa Institute of Engineering \& Technology, Palamaner.
}

\begin{abstract}
The present work is carried out on modeling and analysis of container chassis to improve the load carrying capacity of the chassis and reducing the failure of chassis with bending by adding stiffeners to the chassis. The stiffeners rectangular in shape to be placed in between the cross members of the chassis. The stiffeners are to be fastened to the chassis by means of bolts. The design considerations for this study are bending stress and deflection. The static loading condition was carried out for this type of design. The values compared are with the chassis with stiffener and without stiffener. The modeling is developed on proe-5 and analysis is carried out on ansys-14.
\end{abstract}

Keywords: - container chassis, stiffeners, analysis, comparison, proe-5, ansys 14.

\section{INTRODUCTION}

Chassis is one of the important part of the any automobile. It plays crucial role in the heavy load carrying capacity vehicles like containers. It acts as a back bone of the vehicle. The chassis supports the engine, cabin and suspension system of the vehicle. The main function is to carry the maximum load for any designed condition. The chassis is nearly designed for a load of 10 to15 tons. Under this load it may be subjected to shocks, impact loads due to uneven roads. It also absorbs driveline torque endure torque load on uneven road surfaces. The chassis contains cross members of different cross sections. The chassis is of a ladder shape. This type of chassis is better for good downward support of the vehicle. The chassis will be main criteria for capacity of the vehicle. Localized modification for the chassis is also done increasing the length of the chassis to vary the capacity of the vehicle.

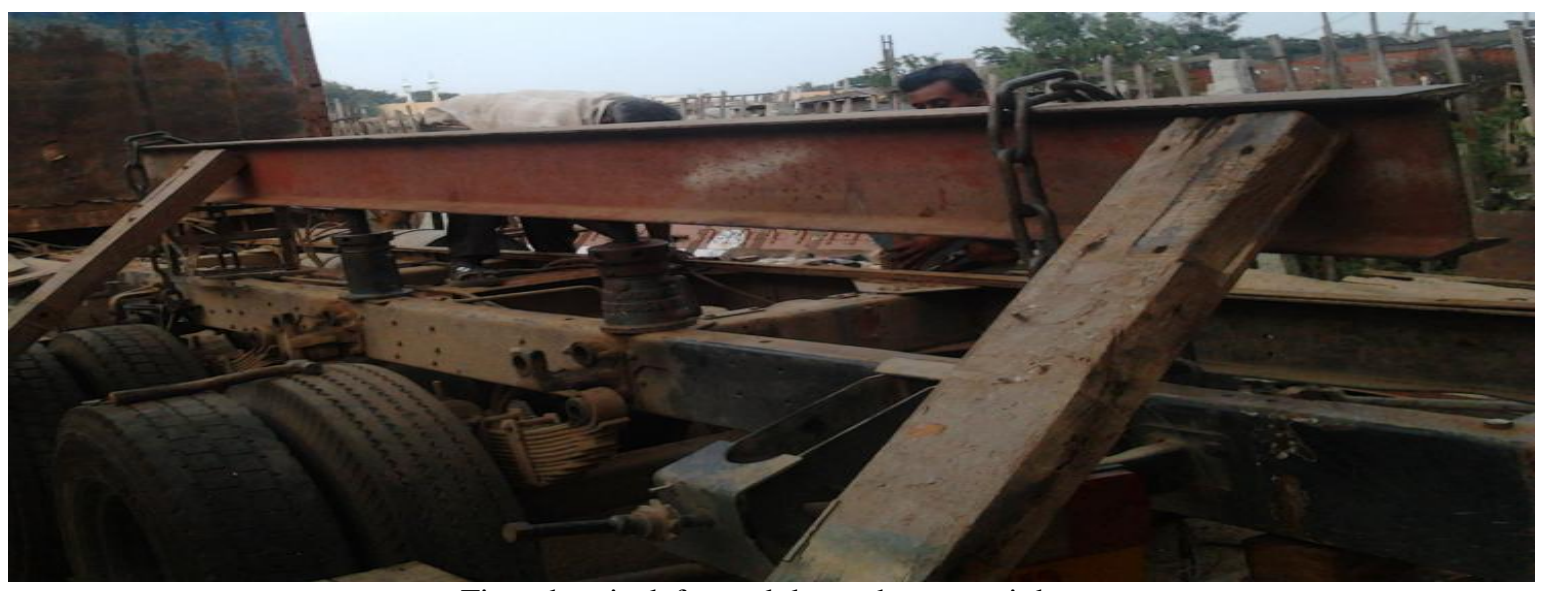

Fig : chassis deformed due to heavy weights

\section{SPECIFICATIONS OF THE CHASSIS}

1. Length of the chassis $-9225 \mathrm{~mm}$

2. Width of the chassis- $860 \mathrm{~mm}$

3 . Heigth of the chassis coumn-230mm

4. Thickness of the column-8mm

5 . Radious of the inside chassis $-8 \mathrm{~mm}$

6. Radious of the out sidechassis $-16 \mathrm{~mm}$

6. No.of cross members-7

7. Back over hung-2770mm

8 . Front over hung-1450mm

9. Length of the flange- $80 \mathrm{~mm}$ 
III.

\section{STIFFNER}

Stiffeners are attached to the beams to give to chassis the stiffness against plane deformation. These stiffeners are of two types - transverse stiffeners and longitudinal stiffeners. The transverse stiffeners are support the beams in standing vertical position. These transverse stiffeners are normal to the span direction of the beam. The longitudinal stiffeners support the beams by horizontal position. These stiffeners are aligned with the span direction of the beams. Stiffeners are attached to the beams by one side or double. Stiffeners are single, double or multi leg stiffeners are in usage.

The dimensions for stiffeners are used for chassis are as follows:
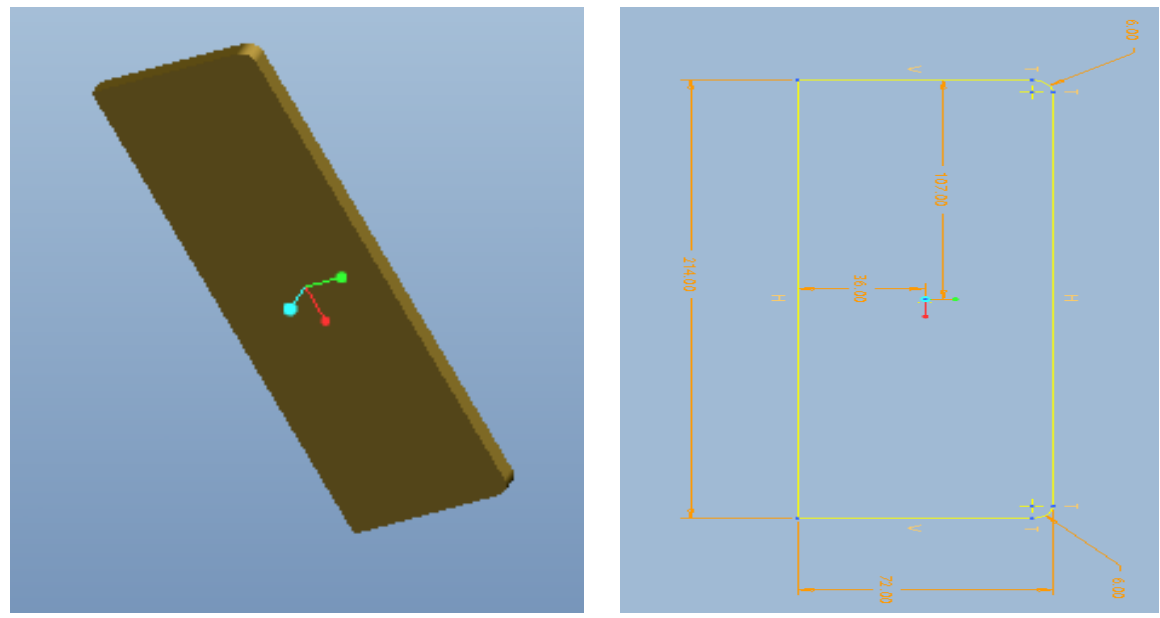

Fig: 2 and 3 dimensional view of the stiffener

IV. MODELLING OF THE CHASSIS

The modeling of the chassis is carried out on proe wild fire5.0. the three dimensional object of chassis is as follows.

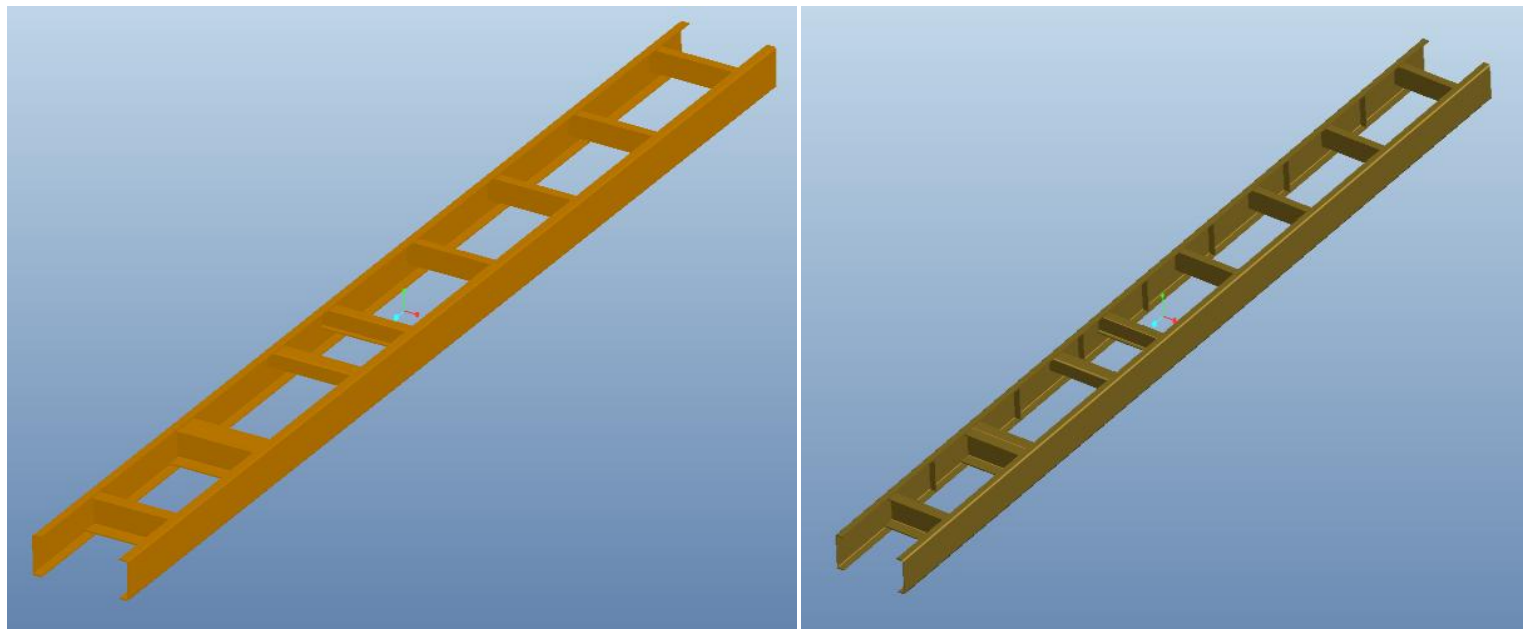

Fig: modeling of the chassis with and without stiffener

V.

FINITE ELEMENT METHOD

Finite element structural analysis is a method of study of the behavior of a structure under particular load and displacement conditions. The finite element modeling is generalization of the displacement or matrix method of structural analysis to two and three-dimensional problems. The basic concept of FEM that structure to be analyzed is considered to be an assemblage of discrete pieces called "elements" that are connected together at a finite number of points or nodes. The finite element is a geometrically simplified representation of a small part of the physical structure. Discrediting the structure requires experience and complete understanding of the behavior of the structure can behave like a beam, truss, plate, and shell. The finite element method for chassis is as follows. 


\section{ANALYSIS OF CHASSIS WITH OUT STIFFNER}

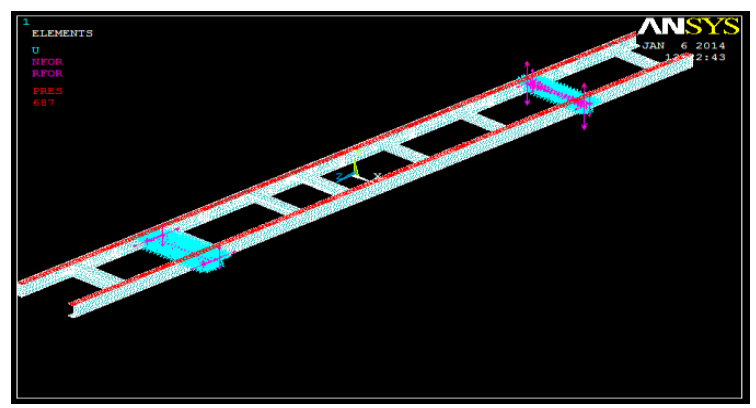

Fig:Boundary condition of the chasssis

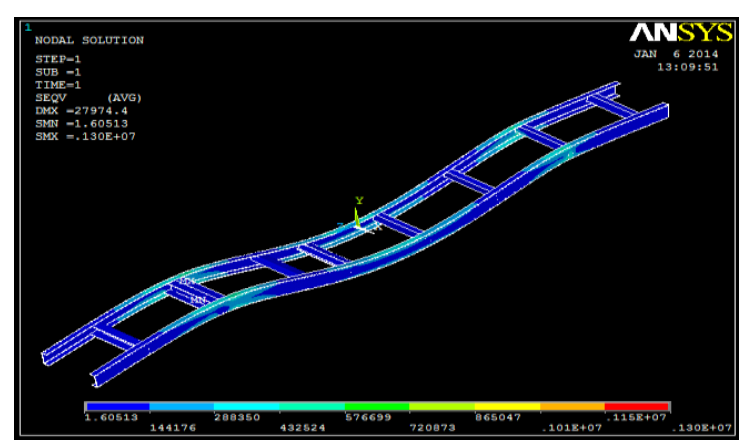

Fig: Vonmisses stress of chassis

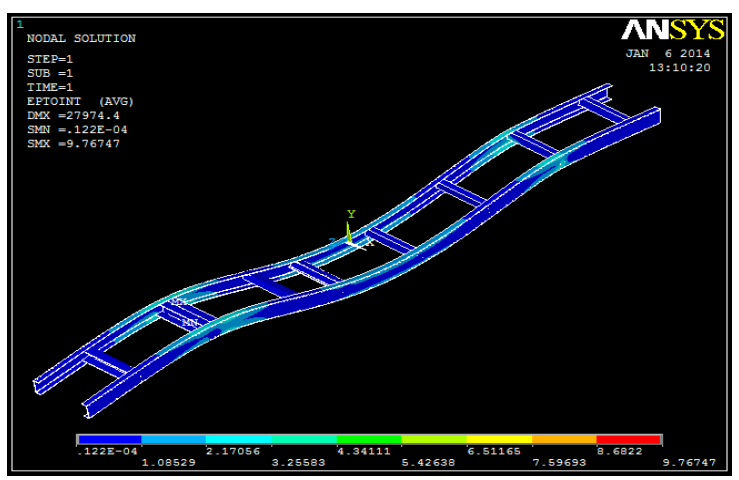

Fig: Total mechanical strain intensity intensity

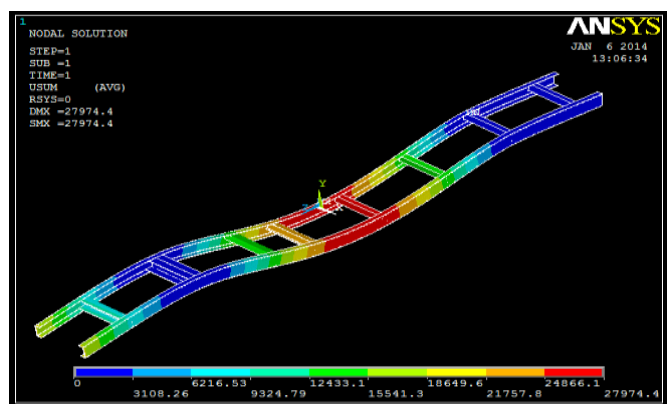

fig: Displacement vector sum of dof

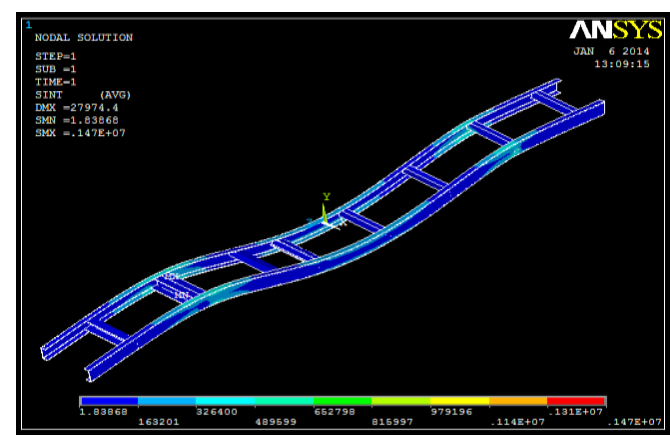

fig: stress intensity of the chassis

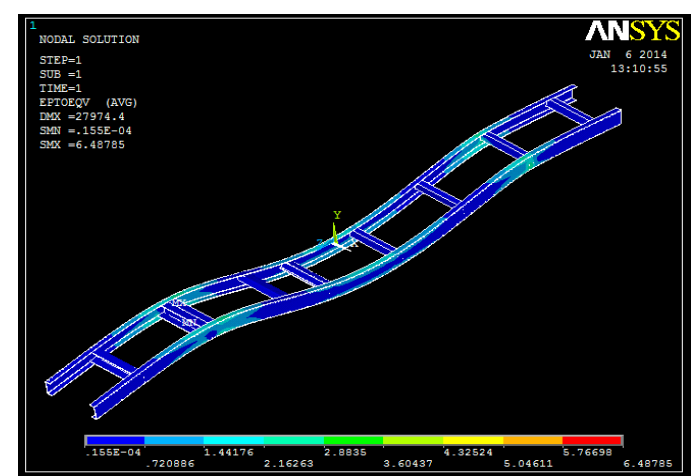

Fig: vonmisses total mechanical strain

\section{ANALYSIS OF CHASSIS WITH STIFFNER}

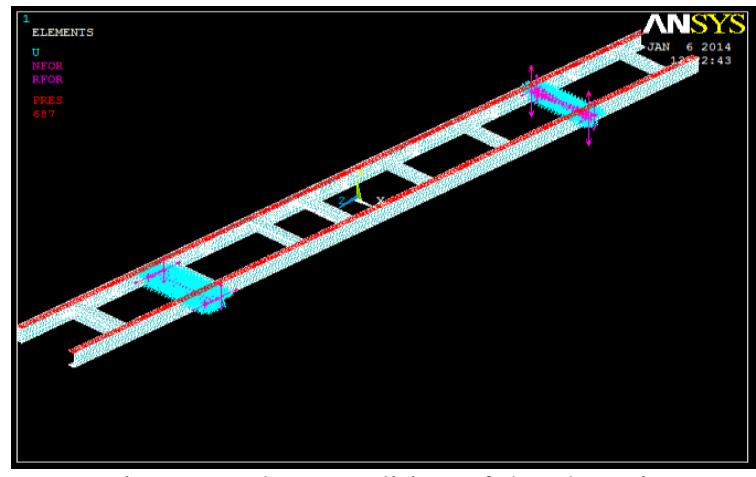

Fig: Boundary condition of the chasssis

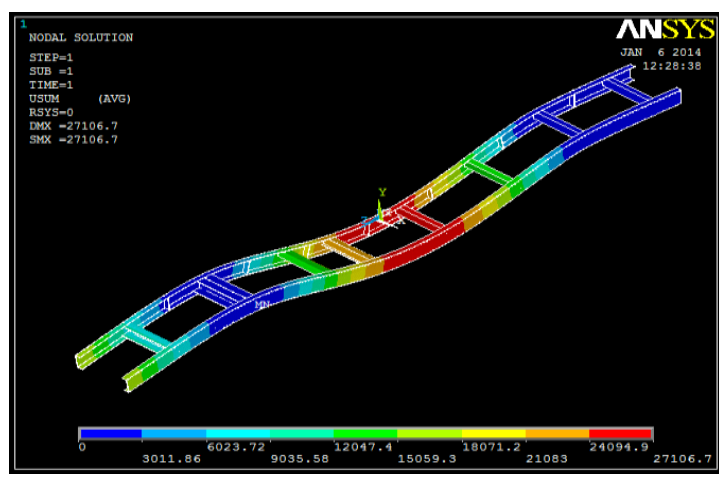

Fig: Displacement vector sum of dof solution 


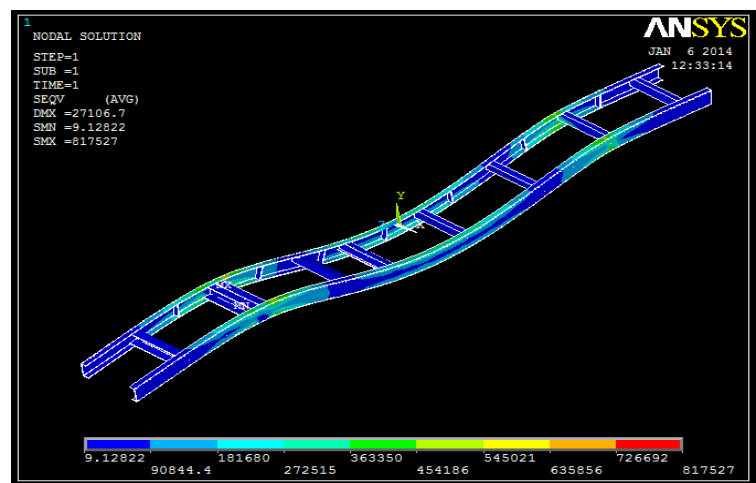

Fig: vonmisses stress of the chassis

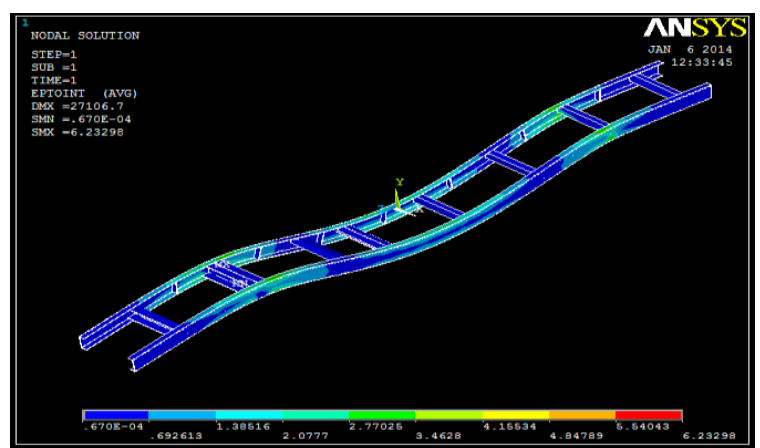

Fig: Total mechanical strain intencity

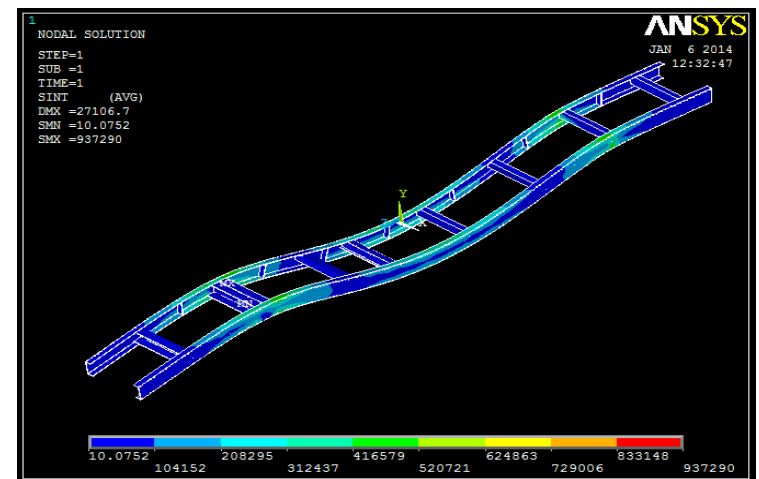

Fig: stress intencity

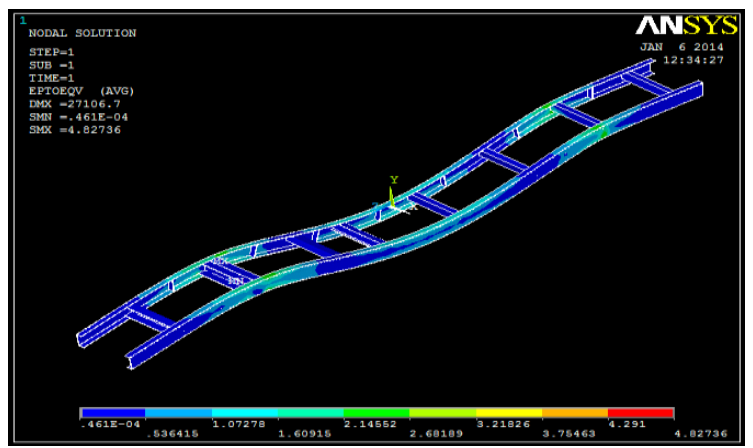

Fig: vonmisses total mechanical strain intencity

VIII.

RESULT

\begin{tabular}{|l|l|l|l|}
\hline & $\begin{array}{l}\text { Vonmisses } \\
\text { stress }\left(\mathbf{N} / \mathbf{m m}^{2}\right)\end{array}$ & $\begin{array}{l}\text { Stress } \\
\text { intencity }\left(\mathbf{N} / \mathbf{m m}^{2}\right)\end{array}$ & $\begin{array}{l}\text { Deflection } \\
(\mathbf{m m})\end{array}$ \\
\hline With out stiffener & $\mathbf{1 3 0 0 0 0 0}$ & $\mathbf{1 4 7 0 0 0 0}$ & $\mathbf{9 . 7 6}$ \\
\hline With stiffener & $\mathbf{8 1 7 5 2 7}$ & $\mathbf{9 3 7 2 9 0}$ & $\mathbf{6 . 2 3}$ \\
\hline
\end{tabular}

IX. CONCLUSION

$>\quad$ The reduction of vonmisses stress in chassis having stiffener up to the extent of $37.11 \%$ was observed when compare to the chassis without stiffener.

$>\quad$ The stress intensity can reduced up to $36.23 \%$.

$>\quad$ The deflction can be reduced by $36.16 \%$.

\section{Journal Papers:}

\section{REFERENCES}

[1] Patel Vijay Kumar ${ }^{1}$ V. Prof. R. I. Patel ${ }^{2}$, Structural Analysis of Automotive Chassis Frame, World Journal of Science and Technology 2(4):05-08 2012.

[2] Sairam Kotari ${ }^{1}$, V.Gopinath ${ }^{2}$, static and dynamic analysis on tetra chassis International Journal of Modern Engineering Research (IJMER) Vol.2, Issue.1

[3] Patel Vijay Kumar ${ }^{1}$ V. Prof. R. I. Patel ${ }^{2}$ Structural Analysis of Automotive Chassis Frame and Design Modification for Weight Reduction, International Journal of Engineering Research \& Technology (IJERT) Vol. 1 Issue 3, May - 2012 ISSN: 2278-0181.

[4] Goolla Murali ${ }^{1}$. Subramanyam. $B^{2}$ Dulam Naveen ${ }^{3}$ Design Improvement of a Truck Chassis based on Thickness, altair technology conference.

Books:

[5] Edmund F. Gaffney III and Anthony R. Salinas, Introduction to Formula SAEâ Suspension and Frame Design analysis (University of Missouri).

[6] N.R.HEMA KUMAR A Text Book on Automobile Chassis and Body Engineering, Introduction to Formula SAEâ Suspension and Frame Design analysis (University of Missouri). 